\title{
Home mechanical ventilation: back to basics
}

\author{
Sunghoon Park' ${ }^{1}$ Eui-Sik Suh ${ }^{2}$ \\ ${ }^{1}$ Department of Pulmonary, Allergy and Critical Care Medicine, Hallym University Sacred Heart Hospital, Anyang, Korea; ${ }^{2}$ Lane Fox Respiratory Service, Guy's \\ and St Thomas' NHS Foundation Trust, St Thomas' Hospital, London, UK
}

Over recent decades, the use of home mechanical ventilation (HMV) has steadily increased worldwide, with varying prevalence in different countries. The key indication for HMV is chronic respiratory failure with alveolar hypoventilation (e.g., neuromuscular and chest wall disease, obstructive airway diseases, and obesity-related respiratory failure). Most modern home ventilators are pressure-targeted and have sophisticated modes, alarms, and graphics, thereby facilitating optimization of the ventilator settings. However, different ventilators have different algorithms for tidal volume estimation and leak compensation, and there are also several different circuit configurations. Hence, a basic understanding of the fundamentals of HMV is of paramount importance to healthcare workers taking care of patients with HMV. When choosing a home ventilator, they should take into account many factors, including the current condition and prognosis of the primary disease, the patient's daily performance status, time (hr/day) needed for ventilator support, family support, and financial costs. In this review, to help readers understand the basic concepts of HMV use, we describe the indications for HMV and the factors that influence successful delivery, including interface, circuits, ventilator accessories, and the ventilator itself.

Key Words: basic; home; mechanical; ventilators

\section{INTRODUCTION}

The prevalence of and indications for home mechanical ventilation (HMV) are highly variable across populations [1,2]; however, over recent decades, the number of patients receiving HMV has increased worldwide. The EUROVENT survey reported a prevalence of HMV in 2005 of 6.6 per 100,000 patients (range, 0.1-17.0 per 100,000 patients), across European countries, with neuromuscular and lung/airway diseases being the most common diagnosis [1]. By contrast, in Australia and New Zealand, obesity hypoventilation syndrome and neuromuscular disease (NMD) were the most common indications [3]. In South Korea, the prevalence was 9.3 per 100,000 patients and NMD, the most common diagnosis, accounted for $42.0 \%$ of HMV patients based on Korean National Health Service Insurance data [4].

The key indication for HMV is chronic ventilatory insufficiency $[5,6]$. This may arise from NMD, obstructive airway diseases, or obesity-related respiratory failure. However, with advances in critical care management, there is an increasing number of patients who survive acute respiratory failure (e.g., due to acute respiratory distress syndrome), and some of them are required to use HMV [5]. Furthermore, as the population ages, the need for ongoing mechanical ventilation in the home or in long-term care facilities is likely to increase.

\section{Review Article}

Received: July 10, 2020

Revised: August 17, 2020

Accepted: August 27, 2020

\section{Corresponding author}

Sunghoon Park

Department of Pulmonary, Allergy and Critical Care Medicine, Hallym University Sacred Heart Hospital, 22 Gwanpyeong-ro 170beon-gil, Dongan-gu, Anyang 14068, Korea Tel: +82-31-380-3715

Fax: +82-31-380-3973

E-mail: f2000tj@gmail.com

Copyright (@) 2020 The Korean Society of Critical Care Medicine

This is an Open Access article distributed under the terms of Creative Attributions Non-Commercial License (https:// creativecommons.org/li-censes/by-nc/4.0/ which permits unrestricted noncommercial use, distribution, and reproduction in any medium, provided the original work is properly cited. 
In light of the rising prevalence of HMV, and the increasing number and complexity of available HMV devices [7-9], a basic understanding of the fundamentals of HMV is of paramount importance to physicians and nurses involved in pulmonary and critical care medicine. In this review, we describe the indications for HMV and the factors that influence successful delivery, including interface, circuits, and the ventilator itself.

\section{INDICATIONS FOR HMV}

The key indication for HMV is chronic respiratory failure arising from alveolar hypoventilation. While the causes of chronic respiratory failure are diverse, they broadly fall into three categories: (1) neuromuscular and chest wall disease, (2) obstructive airway diseases such as chronic obstructive pulmonary disease (COPD), and (3) obesity-related respiratory failure.

\section{Neuromuscular Disease}

Common congenital neuromuscular causes of respiratory failure include primary muscular dystrophies (e.g., Duchenne muscular dystrophy, myotonic dystrophy, and Becker muscular dystrophy) and diseases of the motor neurons such as spinal muscular atrophy. Of the acquired NMDs, amyotrophic lateral sclerosis (ALS), spinal cord injury, and chronic inflammatory demyelinating neuropathies are perhaps the most prominent among patients requiring HMV.

$\mathrm{HMV}$, in combination with assisted cough techniques and nutritional support through gastrostomy insertion, has contributed to a marked improvement in prognosis over the last three decades for patients with Duchenne muscular dystrophy, with patients now frequently surviving into their fourth decade [10]. Age at initiation of HMV is an important prognostic indicator, with patients requiring noninvasive ventilation (NIV) before 17 years having a worse prognosis than those starting NIV at an older age [11]. Respiratory surveillance is mandatory, with measurements of vital capacity, noninvasive measures of respiratory muscle capacity (maximal inspiratory and expiratory pressures), as well as nocturnal oximetry and capnography. NIV should be initiated when nocturnal hypoventilation is evident, although earlier initiation may be considered in the presence of significant respiratory compromise. With improving survival among patients with muscular dystrophy, cardiac morbidity and mortality are increasing and regular evaluation of cardiac function is important.

ALS is an increasingly common indication for the initiation of HMV. It is characterised by progressive degeneration of both upper and lower motor neurons and presents initially with

\section{KEY MESSAGES}

- The key indication for home mechanical ventilation is chronic respiratory failure with alveolar hypoventilation (e.g., neuromuscular and chest wall disease, obstructive airway diseases, and obesity-related respiratory failure).

- Different ventilators have different algorithms for tidal volume estimation and leak compensation, and there are also several different circuit configurations.

- When choosing a home ventilator, clinicians should take into account many factors, including the current condition and prognosis of the primary disease, the patient's daily performance status, time ( $\mathrm{hr} /$ day) needed for ventilator support, family support, and financial cost.

predominant bulbar or limb weakness. Median survival following diagnosis is between 2 and 3 years, and respiratory failure is an inevitable consequence of the condition. NIV should be offered in the presence of orthopnoea, symptomatic sleepdisordered breathing, or daytime hypercapnia, with an associated reduction in forced vital capacity to less than $80 \%$ of predicted or a sniff nasal inspiratory pressure of less than 60 $\mathrm{cm} \mathrm{H}_{2} \mathrm{O}$ [12]. Only one randomised controlled trial has evaluated the survival benefit of NIV in patients with ALS. Bourke and colleagues assigned 92 patients with ALS and daytime hypercapnia and orthopnoea to NIV or standard care. Median survival was 219 days in the NIV group compared with 171 days in the control group, with the greatest advantage seen in patients without bulbar involvement [13]. Bulbar-onset ALS is known to be associated with NIV intolerance [14]. However, with careful titration of ventilation pressures, the majority of patients with bulbar-onset ALS can be successfully established on NIV [15].

\section{Obstructive Lung Disease}

COPD is a common cause of chronic respiratory failure. $\mathrm{Al}$ though the benefits of acute NIV in patients with acute hypercapnic respiratory failure are well-established, both in the intensive care unit and the medical ward [16-19], evidence has only recently emerged of the role of HMV in COPD patients with severe chronic hypercapnia. Köhnlein et al. [20] randomly assigned 200 patients with COPD and arterial carbon dioxide tensions $\left(\mathrm{PaCO}_{2}\right)$ greater than $53 \mathrm{~mm} \mathrm{Hg}$ to either nocturnal HMV or standard care and found that HMV led to a significant improvement in survival, exercise capacity, and quality of life. Murphy and colleagues demonstrated an improvement in admission-free survival in patients who remained severely 
hypercapnic $\left(\mathrm{PaCO}_{2}>53 \mathrm{~mm} \mathrm{Hg}\right)$ between 2 and 4 weeks following an episode of acute hypercapnic respiratory failure requiring NIV and who were assigned to nocturnal NIV and longterm oxygen therapy [21]. Hence in patients with COPD, home nocturnal NIV should be reserved for patients with chronic severe hypercapnia, either in the stable state or following recovery from an episode of decompensated hypercapnic respiratory failure.

\section{Obesity-Related Respiratory Failure}

A recent analysis of national health insurance data did not find that HMV was used to treat obesity-related respiratory failure in South Korea. However, with rising levels of obesity in South Korea, it is important for clinicians to be aware of obesity hypoventilation syndrome (defined as a body mass index $>30 \mathrm{~kg} / \mathrm{m}^{2}$, daytime hypercapnia, and the presence of sleepdisordered breathing) as a potential cause of chronic respiratory failure for which the treatment is either nocturnal continuous positive airway pressure (CPAP) or NIV [22].

\section{INTERFACE}

HMV may be delivered noninvasively or invasively via tracheostomy.

\section{Noninvasive Ventilation}

The choice of an interface plays a crucial role in ensuring adherence to NIV. A vast range of interfaces are currently available, with oronasal (or full-face) masks being the preferred choice for optimal delivery of pressure support. Nasal masks often provide greater comfort but are limited by their inability to deliver consistent positive airway pressure when the mouth is open. This can be mitigated to a certain extent using a chin strap to hold the mouth closed. Both nasal and oronasal interfaces may cause nasal bridge pressure sores and ulceration with chronic use; it is important to be vigilant to this risk and to provide cushioned dressings to protect patients' nasal bridge. Total face masks that cover the eyes, as well as the nose and mouth, can also help to avoid nasal bridge pressure ulcers.

\section{Invasive Ventilation}

There are several reasons why invasive mechanical ventilation via a tracheostomy tube may be the preferred HMV method. Firstly, tracheostomy ventilation with the cuff inflated can ensure reliable pressure support, without the often-significant unintentional leaks associated with noninvasive interfaces, thereby enabling optimal ventilation. This is particularly important for patients with a 24-hour ventilation requirement, for whom continuous NIV may be unacceptable. Secondly, patients with bulbar dysfunction or copious retained secretions may be at risk of aspiration. Finally, tracheostomy ventilation is necessary in patients with depressed consciousness who are unable to protect their airway. A high secretion burden and poor bulbar function may require the tracheostomy tube cuff to remain inflated at all times in some patients, while others may be able to tolerate periods of having the cuff down to communicate and eat.

\section{TYPE OF HOME VENTILATOR}

Home ventilators can be divided into two categories depending on patients' clinical requirements: life-support or life-sustaining ventilators (Table 1). Life-support ventilators are for patients who usually need ventilator support, invasively or noninvasively, for $>16$ hours per day. These devices seem to be appropriate for highly ventilator-dependent patients (i.e.,

Table 1. Comparison of life-support and life-sustaining (non-life support) ventilators

\begin{tabular}{|c|c|c|}
\hline Variable (item) & Life-support ventilator & Life-sustaining ventilator \\
\hline Interface & Tracheostomy or mask & Mask \\
\hline Hours of use per day & $>16$ hours & $<16$ hours or nocturnal use \\
\hline Primary diagnosis & Advanced chronic respiratory failure & Chronic stable COPD, OHS, ALS, early DMD \\
\hline Circuit configuration & $\begin{array}{l}\text { Double-limb circuit, single-limb circuit with an exhalation valve } \\
\text { sometimes, single-limb with a leak port (i.e., vented circuit) }\end{array}$ & Single-limb circuit with a leak port (i.e., any vented circuit) \\
\hline Mode & Various modes including assisted and controlled modes & S, S/T, PSV, PCV, CPAP, or volume-assured pressure support \\
\hline Monitoring & Full range & Basic range \\
\hline Internal battery & $3-9$ hours & Irrelevant \\
\hline
\end{tabular}

COPD: chronic obstructive pulmonary disease; OHS: obesity hypoventilation syndrome; ALS: amyotrophic lateral sclerosis; DMD: Duchenne muscular dystrophy; S: spontaneous; S/T: spontaneous/timed; PSV: pressure support ventilation; PCV: pressure control ventilation; CPAP: continuous positive airway pressure. 
bedridden or severely debilitated patients) or those who have advanced respiratory failure. However, life-sustaining (or nonlife-support) ventilators are for patients who need ventilator support, usually noninvasively, for a few hours a day or only for nocturnal use.

Positive pressure ventilation via an invasive airway was developed in the 1960s $[23,24]$. The first-generation (positive pressure) home ventilators were piston-driven units that provided only volume-controlled breaths (e.g., LP-3 and PLV series) $[23,24]$. However, the second-generation ventilators were usually turbine-driven and provided various modes such as pressure control ventilation (PCV), pressure support ventilation (PSV), and CPAP modes (e.g., T-bird series, LTV series, and HT 50). As well as improvements in battery options and portability, positive end-expiratory pressure (PEEP) control integrated into the ventilator came into use. The third-generation ventilators feature increased portability and enhanced graphics, which are helpful for troubleshooting problems (e.g., PB540, Trilogy100, and iVent101, etc.) [23,24].

Since the success of NIV in patients with obstructive sleep apnoea or NMD in the 1980s [25-29], the production of small pressure- or volume-targeted ventilators, which were lightweight and easy to use, was stimulated. In particular, the introduction of microprocessors in the 1980s led to the development of digital control of flow valves, which are now used in many ventilators and are able to shape the pressure, volume, and flow waveforms [30]. Currently, most home ventilators are microprocessor-controlled, electrically powered units that use a blower (or turbine) to generate gas flow. In a bench study, in terms of triggering and pressurization, turbine-driven home ventilators were found to be as efficient as critical care ventilators driven by high-pressure wall gas (Figure 1) [31].

As mentioned above, early portable volume ventilators were originally designed for patients who required long-term assisted ventilation. These ventilators had relatively basic functionality (e.g., pressure-triggering, limited flow delivery, and basic alarms) with no graphics [23]. Furthermore, PEEP was generated not by a turbine, but through an external threshold resistor connected to an exhalation valve in-circuit, which can increase the patient's work of breathing (WOB). Although pressure-targeted ventilators are now used more frequently than volume ventilators, volume ventilators can occasionally be helpful in generating stacked breaths (i.e., to achieve high tidal volumes [Vts] with high pressures) in patients with NMD $[23,24]$

Pressure-targeted ventilators are flow- and time-triggered, pressure-limited, and flow- and time-cycled. They can deliver both inspiratory positive airway pressure (IPAP) and expiratory positive airway pressure (EPAP), and Vt depends on the difference between IPAP and EPAP, the patient's inspiratory effort, and lung mechanics. One of the advantages of portable pressure-targeted ventilators, compared with volume-targeted or critical care ventilators, is that flow sensors can continuously monitor and adjust the flow, while taking into account the patient's respiratory effort and leaks $[24,32]$.

\section{CIRCUIT SYSTEMS}

There are three types of circuit systems [33]. In general, unlike double-limb circuit systems, the two single-limb systems can be used interchangeably with each ventilator. However, physicians and nurses should be aware of dead space and compliance (i.e., the compressible volume) of the patient circuit chosen. It is known that as much as 3 to $5 \mathrm{~mL} / \mathrm{cm} \mathrm{H}_{2} \mathrm{O}$ can be compressed in the ventilator circuit. Hence, in paediatric patients where Vt is very small, if the compliance of the circuit is large, the real Vt delivered in volume-controlled mode will be smaller than the preset Vt [7]. Most modern ventilators can measure the compressible volume during the pre-use check and adjust for the effect of compressible volume automatically (i.e., automatic compliance compensation).

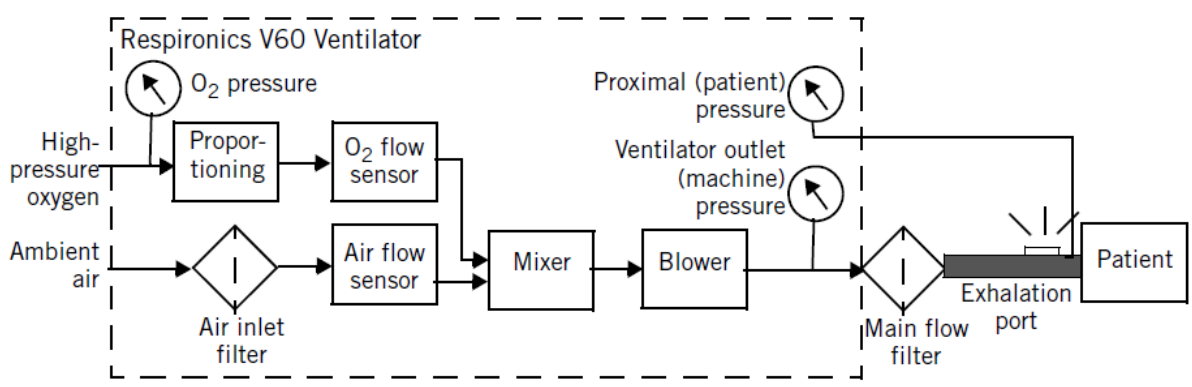

Figure 1. Diagram of V60 (Philips Respironics), which is a dedicated critical care noninvasive ventilator. This ventilator has a blower and single-limb vented circuit. 


\section{Single-Limb Circuit with a Leak Port (i.e., Vented Circuit)}

Currently, many home ventilators use this circuit system due to its simplicity and capability to compensate for leaks. Home ventilators using this configuration have an algorithm for compensating for leaks, and $\mathrm{CO}_{2}$ is vented out through the leak port (i.e., passive exhalation) (Figure 2A) [33]. With this system, ventilators usually deliver two pressures (IPAP and EPAP), so there is a continuous flow through the entire breathing cycle inside the circuits. However, these machines do not measure inspiratory or expiratory Vts directly, but rather estimate them using proprietary algorithms. $\mathrm{CO}_{2}$ removal (or rebreathing) can be affected by EPAP, intentional and nonintentional leaks, and supplemental oxygen entrained in the mask. However, importantly, when switching to a mask with a different leak (e.g., a vented mask), the ventilator may fail to deliver the same preset Vt or pressure; hence, adjustment of the pressure level is needed.

\section{Single-Limb Circuit with an Exhalation Valve (i.e., Non-Vented Circuit)}

In this type of system, an exhalation valve can be placed at the distal end of the inspiratory circuit (Figure 2B) or at the end of a short expiratory limb. This valve (or active exhalation valve) has an on-off function and often works as a PEEP regulator (i.e., expiratory threshold resistor). This type of circuit allows complete elimination of $\mathrm{CO}_{2}[33,34]$; that is, all exhaled gas is vented out and does not enter the ventilator. Hence, there is no expiratory flow wave in the monitor if it does not have a flow sensor in the circuit, and these units only measure and
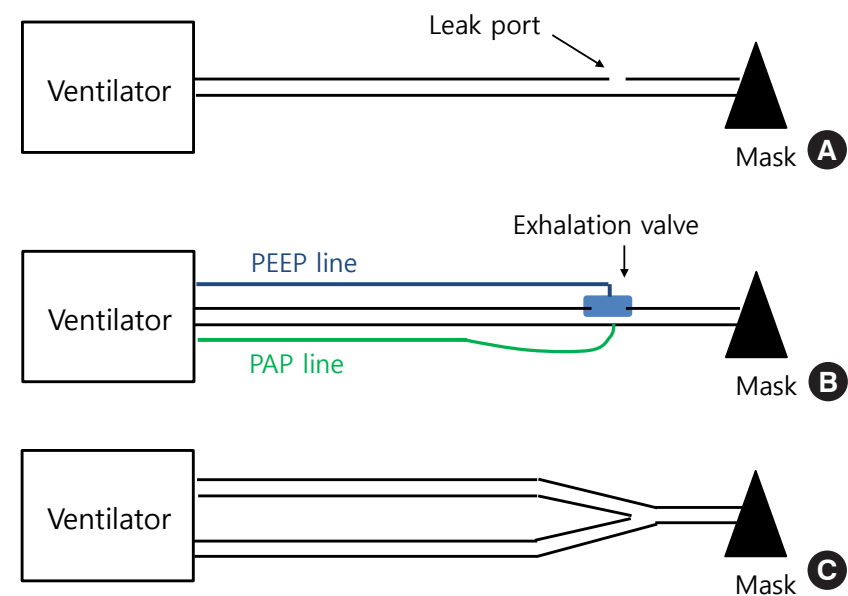

Figure 2. Three circuit configurations. (A) A single-limb vented circuit (with a leak port). (B) A single-limb non-vented circuit (with an active exhalation valve). (C) A double-limb circuit. PEEP: positive end-expiratory pressure; PAP: proximal airway pressure. provide inspiratory Vt. In pressure-targeted modes, some devices display the delivered pressures as above PEEP (or pressure support) and PEEP, while others as display the pressures as IPAP and EPAP, respectively.

In patients who need a high IPAP, there can be large leaks (intentional or unintentional leaks), which result in both decreased oxygenation and decreased $\mathrm{Vt}$ (i.e., increased $\mathrm{PaCO}_{2}$ ). In this case, a non-vented circuit may be preferred to a vented circuit [34]. However, the ability to compensate for unintentional leaks can be suboptimal with non-vented circuits in patients using volume-guaranteed modes (e.g., volume-assured pressure support), thus leading to decreased inspiratory pressure (or delivered Vt) $[35,36]$. Therefore, there is a possibility of misinterpretation of unintentional leaks as an increase in $\mathrm{Vt}$ [37]. For this reason, caution should be taken when using this mode.

\section{Double-Limb Circuit}

This type of circuit is non-vented and is composed of inspiratory and expiratory limbs (Figure 2C) [33]. In the proximal ends (i.e., toward the ventilators), the two limbs are connected to the inspiratory and expiratory ports, respectively, where each non-rebreathing, flow-control valve is positioned inside the ventilators. Their distal end is connected, through a Y-piece, to the patient interface. These circuits have no leak port and are used with non-vented mask (in NIV) or tracheostomy. They measure both inspiratory and expiratory Vts. Several home ventilators, usually life-support ones, have a mode for this circuit configuration (T-Bird series, LTV series, PB 540, iVent 101, and Astral 150) [23].

\section{AIR LEAKS}

There are two types of leaks: intentional and unintentional. Intentional leaks occur through the leak port of a single limb circuit and are necessary for $\mathrm{CO}_{2}$ removal. By contrast, unintentional leaks occur around masks or sites other than the leak port (e.g., aerophagia). Although the estimation of leaks is not standardized among different ventilators, leaks are displayed as flow (L/min) in a single-limb circuit with a leak port, and as percentage (\%) in a double-limb circuit.

In an experimental study using simulated lung conditions by Borel et al. [38], intentional leaks ranged from 30 to $45 \mathrm{~L} /$ min for an IPAP of $14 \mathrm{~cm} \mathrm{H} \mathrm{H}_{2} \mathrm{O}$ and an EPAP of $4 \mathrm{~cm} \mathrm{H}_{2} \mathrm{O}$, and the authors claimed that the capacity of ventilators to achieve and maintain IPAP was impaired when intentional leaks increased, especially above $40 \mathrm{~L} / \mathrm{min}$ [38]. Another clinical study 
demonstrated no significant differences in the amount of total leaks (i.e., intentional plus unintentional leaks) between patients with different diagnoses of chronic respiratory failure. In that study, the total leaks ranged from 28.2 to $67.7 \mathrm{~L} / \mathrm{min}$ [39].

Portable pressure-targeted ventilators have the ability to compensate for these leaks [40]. However, high leaks can cause patient-ventilator dyssynchrony, such as ineffective triggering, auto-triggering, increased pressurization time, and delayed cycling, which can lead to increased WOB for the patient. It can also be associated with decreased oxygen concentration (or decreased $\mathrm{CO}_{2}$ removal) in the mask $[40,41]$.

\section{MONITORING SYSTEM}

Recent ventilators have incorporated commercial software (built-in software) that provides information on variables such as pressure and flow in the monitors, which provide important information about patient-ventilator interactions, thereby facilitating the optimization of the ventilator settings. In most home ventilators, flow and pressure are directly measured by ventilators, but other parameters are derived from the analyses of the flow or pressure. The ability of a home ventilator (or NIV) to maintain a stable Vt depends on both pressurization capacity and an accurate estimation of Vt and leaks.

\section{Tidal Volume}

The calculation of Vt differs between vented (i.e., leak port) and non-vented (i.e., active exhalation valve) circuit configurations. In home ventilators with a double-limb circuit, Vt can be directly measured by an internal pneumotachograph. In non-vented single-limb circuits, all the expired gas escapes through the exhalation valve, so these units usually provide only inspiratory $\mathrm{Vt}$ [42]. However, in vented single-limb circuit systems, although both inspiratory and expiratory flows are displayed on the monitor, Vt is not directly measured, but is rather estimated through ventilator-specific algorithms. Since pressure loss (or compressible volume) in the circuits can decrease the Vt delivered to a patient, some ventilators have an algorithm (for the pre-use test) or proximal pressure sensors to determine the values [43].

\section{Leak Estimation}

In the presence of continuous leak flow, the pneumotachograph inside the ventilator monitors both Vt and leaks. The relationship between the total flow, leak flow, and patient flow is presented in the following equation:

- Total flow = patient flow+leak flow
Home ventilators can measure leak flows at the end of the patient's breaths, namely transition points between expiration and inspiration when the patient flow is zero; at this time, the entire amount of flow in the system corresponds to leak flow. By using this concept, home ventilators determine resistance (R) according to the following equation:

- $\mathrm{R}$ [resistance] = P [pressure]/F [flow], where $\mathrm{P}$ can be replaced with EPAP.

Then, ventilators apply the $\mathrm{R}$ value throughout the entire cycle to estimate the amount of the leak; hence, the patient flow (Vt) can be estimated. However, a problem is that asymmetrical leakage (i.e., leakage only during either inspiration or expiration) is common, and the R value is not constant. Usually, with inspiratory leaks, the estimated expiratory Vt is overestimated, but with expiratory leaks, the Vt is underestimated by commercial ventilator software [42]. However. in the vented single-limb circuit configuration, some ventilators display figures indicating only unintentional leaks, while others display figures indicating the sum of intentional and unintentional leaks.

Most pressure-targeted ventilators are optimized for use with a vented circuit. Hence, it should be considered that when using a non-vented circuit, compensation for unintentional leaks can be suboptimal.

\section{Triggering}

Ventilator-initiated mandatory breaths are triggered by the preset time. Patient-initiated (i.e., assisted) breaths can be triggered by a variety of mechanisms: pressure-triggering, flowtriggering, volume-triggering, and algorithm-triggering (e.g., Auto-Trak by Philips Respironics) $[33,44,45]$. Flow-triggering is operated through the measurement of flow variations by a flow sensor inside the ventilator (in a single-limb vented circuit) or a proximal flow sensor in the circuit near the patient (in a non-vented single-limb circuit). In a double-limb circuit, a continuous bias flow is provided into the patient circuit and the triggering occurs when the difference between the flow entering and exiting through the circuit equals the preset trigger sensitivity (Figure 3A) [44].

Adjustment of trigger sensitivity and rise time in ventilators can improve patient comfort when triggering the ventilator. However, high levels of leaks, either intentional or unintentional, can interfere with trigger sensitivity. In particular, in paediatric patients, the use of a proximal flow sensor is often recommended to better detect inspiratory flows (i.e., when to trigger or cycle the ventilator), because the flows in paediatric patients are usually lower than those in adults and their unin- 


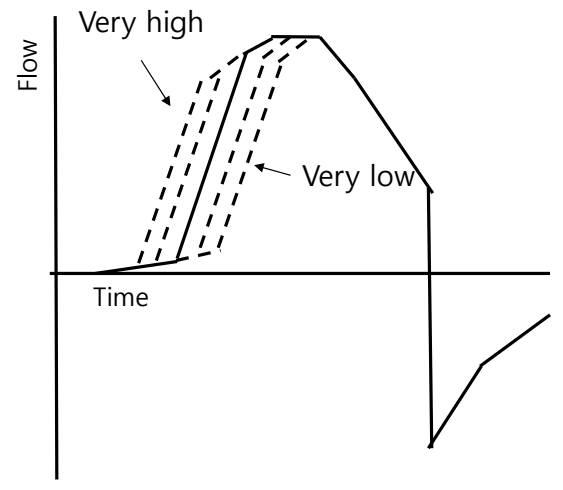

Tigger sensitivity

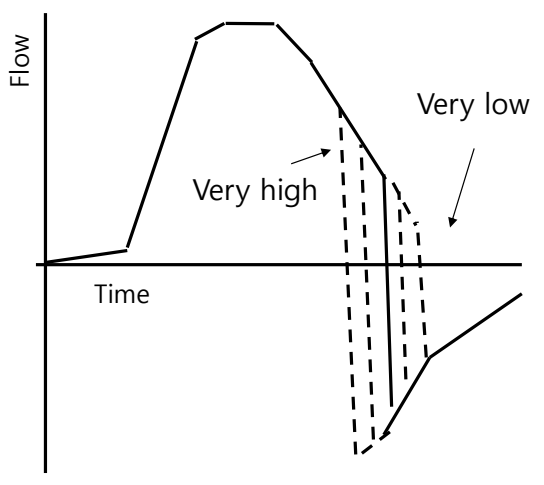

Cycle sensitivity

B

Figure 3. Trigger and cycle sensitivity. (A) Trigger sensitivity: the higher the trigger sensitivity (or a lower absolute threshold value), the faster the breath initiation. (B) Cycle sensitivity: the higher the cycle sensitivity (i.e., a higher percentage of peak inspiratory flow), the faster the termination of the inspiratory phase. The X-axis indicates time (sec) and the Y-axis denotes flow (L/min).

tentional leaks are higher (due to the use of uncuffed tracheostomy tubes).

\section{Cycling}

Inspiratory flows can be cycled to expiration by pressure-, volume-, time-, and flow-cycling. Of these methods, flow-cycling and time-cycling are the most frequently used. A breath is flowcycled when the ventilator detects the end of a patient's inspiratory flow (i.e., the percentage of peak inspiratory flow rate) (Figure 3B) and terminates the inspiratory phase, which is used in "spontaneous mode" and "PSV mode") [33,45,46]. However, a breath is time-cycled when the inspiration is terminated after the preset inspiration time is reached, which is used in "timed mode" and "PCV mode").

The occurrence of dyssynchrony in the flow-cycled mode may be corrected by adjustment of rise time, trigger sensitivity, and the threshold of flow cycling (or the minimal and maximal inspiratory time). In patients with intrinsic PEEP, delayed or ineffective inspiratory triggering may be improved by increasing the EPAP to reduce the inspiratory threshold load.

\section{Rise Time}

Current pressure-targeted ventilators have a function of controlling the rise time (Figure 4), which refers to the amount of time required to reach the target IPAP. Although no data have shown its beneficial effects, the use of rise time may enhance patient comfort and decrease WOB. For patients with COPD, the rise time needs to be decreased, compared to normal or NMD patients, to meet their demand for higher inspiratory flow (e.g., $150 \mathrm{~ms}$ vs. $300 \mathrm{~ms}$ ) [47].

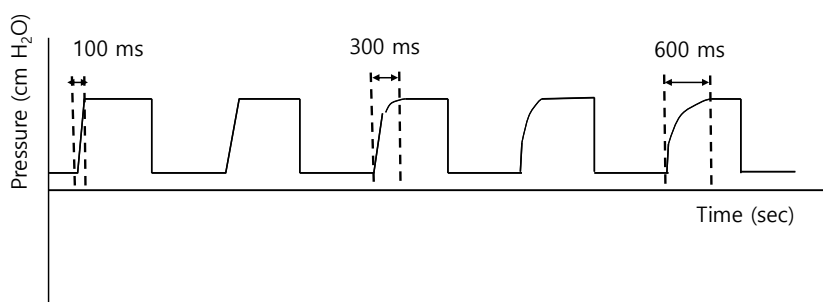

Figure 4. Rise time. The $\mathrm{X}$-axis indicates time (sec) and the $\mathrm{Y}$-axis denotes pressure $\left(\mathrm{cm} \mathrm{H}_{2} \mathrm{O}\right)$.

\section{Ramp}

The ramp function is one of the several comfort features of pressure-targeted ventilators. This allows positive pressure to increase gradually to a prescribed level, by an increment of 1 , 2, or $3 \mathrm{~cm} \mathrm{H}_{2} \mathrm{O}$, over a set period (usually between 0 and 45 minutes). This is more likely to be used for patients who require a ventilator for intermittent or nocturnal use as it is easier for them to fall asleep before reaching the preset ventilation pressures $[24,47]$.

\section{Expiratory Positive Airway Pressure}

EPAP is important for $\mathrm{CO}_{2}$ removal during exhalation in a system using a single-limb vented circuit. Previous studies showed that an EPAP of $4 \mathrm{~cm} \mathrm{H}_{2} \mathrm{O}$ or more can improve continuous gas flow through the system and minimize $\mathrm{CO}_{2}$ rebreathing $[48,49]$. Although the addition of an exhalation valve to the circuit (i.e., a single-limb circuit with an exhalation valve) can be helpful for eliminating $\mathrm{CO}_{2}$ rebreathing, it may increase expiratory airway resistance, leading to increased WOB for some patients. 


\section{OXYGENATION}

Usually, home ventilators use low pressure oxygen and ambient air, contrary to critical care ventilators, which use both gases at high pressure. Supplemental oxygen is usually connected directly to the ventilators (via a low-pressure oxygen inlet) or entrained into the patient circuit. However, oxygen delivery can be inconsistent and does not reach a high fraction of inspired oxygen $\left(\mathrm{FiO}_{2}\right.$; usually $<60 \%$ ). Oxygen concentration is frequently affected by the site of oxygen entrainment, type of leak port, oxygen flow, and breathing pattern, thus leading to difficulty in delivering a precise $\mathrm{FiO}_{2}[7,50]$. Higher levels of ventilator pressure or flows result in lower oxygen concentration. When the leak port is in the mask and oxygen is bled into the mask, the delivered oxygen levels may be the lowest. Hence, whenever any of the variables listed previously are changed, monitoring by pulse oximetry is recommended.

Most life-support ventilators have a module (a sensor), instead of an oxygen blender, to monitor oxygen concentration in the system. However, if a patient requires a high or precise $\mathrm{FiO}_{2}$, a ventilator with an integral oxygen blender should be used (e.g., Trilogy202) [24,50]. It is also usually recommended that due to the risk of fire, when a ventilator is started, the oxygen flow should be turned on after the ventilator is first turned on, but it must be turned off before the ventilator is turned off; unused oxygen must not be accumulated when the ventilator is not operating.

\section{HUMIDIFICATION}

Mucosal drying is associated with increased airway resistance, which can be a cause of patient discomfort and noncompliance with ventilators. Although the cost of care can be increased, the addition of a humidifier may improve patient comfort and compliance with ventilation. Data to support heated humification are sparse, however, with a recent study showing no improvement in adherence to NIV [51]; importantly, the presence of an external heated humidifier led to an appreciable reduction in the delivered inspiratory pressure. Nonetheless, in patients with oronasal dryness during NIV, heated humidification may lead to improved comfort. Heated humidifiers are often sold separately, but some ventilators have an integrated humidifier. Humidifiers should be disconnected when the ventilator is in use while the patient is in transit, such as in a wheelchair.

\section{FILTERS}

Home ventilators are equipped with filters to protect patients and ventilator sensors from particles in the ambient air. They are usually disposable and manufactures recommend that filters are changed regularly.

\section{BATTERIES}

Home ventilators are typically powered by mains electricity, but many devices have an internal battery. It is usually recommended to use the mains electricity supply for the majority of the time, with the battery reserved for transfers or emergencies.

Except for CPAP machines or simple bilevel ventilators, many home ventilators have an internal battery that can last 3 to 9 hours, as well as an external (detachable) battery [52]. A car plug for battery recharging is also available for some ventilators, which is useful for patient transport or traveling.

\section{CHOOSING A VENTILATOR}

When choosing a home ventilator, physicians and respiratory therapists (or nurses) should take into account many factors, including the current condition and prognosis of the primary disease, the patient's daily performance status (i.e., dependent vs. independent), time needed for ventilator support (i.e., continuous vs. intermittent), family support, and financial costs [53]. Although data are very limited, patients who feel comfortable with a particular ventilator are more likely to be compliant with home ventilation than those who do not [54]. Hence, when choosing a ventilator, an evaluation of the patient's perception of the ventilator should be conducted and if possible, the patient should be encouraged to express their feelings [54]; if the patient expresses discomfort with a ventilator, another ventilator can be tested. Moreover, as a patient's condition changes over time, the patient might need a new ventilator (or a new mode).

Another important issue to consider is the circuit configuration. Although home ventilators with a double-limb circuit are the most accurate way to estimate Vt and leaks, these configurations tend to be bulky for practical use at home. Currently, ventilators with a single-limb circuit configuration are more frequently used. So far, studies showed that the best option is single-limb circuit with a leak port (i.e., intentional leak) [36, 37,42]. Again, single-limb configurations with an exhalation valve (i.e., a non-vented circuit) may not perform well in pa- 
tients with mask ventilation (i.e., NIV) [36,37,42].

Life-support ventilators were reported to be used in $77.8 \%$ of patients in South Korea who used HMV [4]. On contrary, in European countries, few patients use those ventilators, mainly patients with a tracheostomy. Life-support ventilators usually have both volume- and pressure-controlled modes and many sophisticated alarms and safety systems. When choosing a ventilatory mode, it should be targeted to the patient's needs. It is reasonable that patients or their family should avoid purchasing devices with excessively complex or sophisticated ventilatory mode options that are rarely used at home.

\section{CONCLUSIONS}

Most modern home ventilators are pressure-targeted and have sophisticated modes, alarms, and graphics, thereby facilitating the optimization of the ventilator settings and troubleshooting many problems. Different ventilators have different algorithms for Vt estimation and leak compensation, and there are also several different circuit configurations. Currently, both for patients ventilated via mask and for those ventilated by tracheostomy, ventilators with a single-limb vented circuit system are frequently used, which are optimized for leak compensation. However, depending on the patient's condition, other circuit configurations can be considered. In particular, for paediatric patients, the issues of a low inspiratory flow and incidence of unintentional leaks (with tracheostomy) should be considered when selecting a ventilator and circuit system.

The use of home ventilators has increased steadily over the last three decades. In the future, with technical developments (e.g., telemedicine) [55] and increasing number of elderly patients with underlying comorbidities, there is likely to be a higher demand for mechanical ventilation at home and in longterm care facilities.

\section{CONFLICT OF INTEREST}

No potential conflict of interest relevant to this article was reported.

\section{ACKNOWLEDGMENTS}

The authors want to thank members of the Korean NIV study group for their contribution into this article: Jae Hwa Cho (Gangnam Severance Hospital, Yonsei University College of Medicine); Tai Sun Park (Hanyang University Guri Hospital); Sei Won Kim (Eunpyeong St. Mary's Hospital, College of Medi- cine, The Catholic University of Korea); Hyung Koo Kang (Inje University Ilsan Paik Hospital); Yoon Mi Shin (Chungbuk National University Hospital); Kwangha Lee (Pusan National University Hospital); Jick Hwan Ha (Incheon St. Mary's Hospital, College of Medicine, The Catholic University of Korea); Young Seok Lee (Korea University Guro Hospital); Youjin Chang (Inje University Paik Hospital); and Won-Il Choi (Kyeimyung University Dongsan Hospital).

\section{ORCID}

Sunghoon Park https://orcid.org/0000-0001-7004-6985

Eui-Sik Suh https://orcid.org/0000-0002-4883-0084

\section{AUTHOR CONTRIBUTIONS}

Conceptualization \& Data curation, Visualization, Writingoriginal draft, review \& editing: all authors.

\section{REFERENCES}

1. Lloyd-Owen SJ, Donaldson GC, Ambrosino N, Escarabill J, Farre R, Fauroux B, et al. Patterns of home mechanical ventilation use in Europe: results from the Eurovent survey. Eur Respir J 2005;25:1025-31.

2. MacIntyre EJ, Asadi L, Mckim DA, Bagshaw SM. Clinical outcomes associated with home mechanical ventilation: a systematic review. Can Respir J 2016;2016:6547180.

3. Garner DJ, Berlowitz DJ, Douglas J, Harkness N, Howard M, McArdle N, et al. Home mechanical ventilation in Australia and New Zealand. Eur Respir J 2013;41:39-45.

4. Kim HI, Cho JH, Park SY, Lee YS, Chang Y, Choi WI, et al. Home mechanical ventilation use in South Korea based on national health insurance service data. Respir Care 2019;64:528-35.

5. Hind M, Polkey MI, Simonds AK. AJRCCM: 100-year anniversary. homeward bound: a centenary of home mechanical ventilation. Am J Respir Crit Care Med 2017;195:1140-9.

6. Simonds AK. Home mechanical ventilation: an overview. Ann Am Thorac Soc 2016;13:2035-44.

7. Kacmarek RM, Malhotra A. Equipment required for home care ventilation. In: Tobin MJ, editor. Principles and practice of mechanical ventilation. 2nd ed. New York: McGraw Hill; 2006. p. 97-127.

8. Battisti A, Tassaux D, Janssens JP, Michotte JB, Jaber S, Jolliet P. Performance characteristics of 10 home mechanical ventilators in pressure-support mode: a comparative bench study. Chest 2005;127:1784-92. 
9. Vitacca M, Barbano L, D’Anna S, Porta R, Bianchi L, Ambrosino N. Comparison of five bilevel pressure ventilators in patients with chronic ventilatory failure: a physiologic study. Chest 2002;122:2105-14.

10. Kieny P, Chollet S, Delalande P, Le Fort M, Magot A, Pereon Y, et al. Evolution of life expectancy of patients with Duchenne muscular dystrophy at AFM Yolaine de Kepper centre between 1981 and 2011. Ann Phys Rehabil Med 2013;56:443-54.

11. Chatwin M, Tan HL, Bush A, Rosenthal M, Simonds AK. Long term non-invasive ventilation in children: impact on survival and transition to adult care. PLoS One 2015;10:e0125839.

12. National Institute for Health and Care Excellence. Motor neurone disease: assessment and management. NICE guideline [NG42]. London: National Institute for Health and Care Excellence [cited 2020 Aug 28]. Available from: https://www. nice.org.uk/guidance/ng42.

13. Bourke SC, Tomlinson M, Williams TL, Bullock RE, Shaw PJ, Gibson GJ. Effects of non-invasive ventilation on survival and quality of life in patients with amyotrophic lateral sclerosis: a randomised controlled trial. Lancet Neurol 2006;5:140-7.

14. Gruis KL, Brown DL, Schoennemann A, Zebarah VA, Feldman EL. Predictors of noninvasive ventilation tolerance in patients with amyotrophic lateral sclerosis. Muscle Nerve 2005;32:808-11.

15. Farrero E, Prats E, Povedano M, Martinez-Matos JA, Manresa F, Escarrabill J. Survival in amyotrophic lateral sclerosis with home mechanical ventilation: the impact of systematic respiratory assessment and bulbar involvement. Chest 2005;127: 2132-8.

16. Brochard L, Isabey D, Piquet J, Amaro P, Mancebo J, Messadi AA, et al. Reversal of acute exacerbations of chronic obstructive lung disease by inspiratory assistance with a face mask. $\mathrm{N}$ Engl J Med 1990;323:1523-30.

17. Meduri GU, Conoscenti CC, Menashe P, Nair S. Noninvasive face mask ventilation in patients with acute respiratory failure. Chest 1989;95:865-70.

18. Plant PK, Owen JL, Elliott MW. Early use of non-invasive ventilation for acute exacerbations of chronic obstructive pulmonary disease on general respiratory wards: a multicentre randomised controlled trial. Lancet 2000;355:1931-5.

19. Strumpf DA, Millman RP, Carlisle CC, Grattan LM, Ryan SM, Erickson $\mathrm{AD}$, et al. Nocturnal positive-pressure ventilation via nasal mask in patients with severe chronic obstructive pulmonary disease. Am Rev Respir Dis 1991;144:1234-9.

20. Köhnlein T, Windisch W, Köhler D, Drabik A, Geiseler J, Hartl $\mathrm{S}$, et al. Non-invasive positive pressure ventilation for the treatment of severe stable chronic obstructive pulmonary disease: a prospective, multicentre, randomised, controlled clinical trial. Lancet Respir Med 2014;2:698-705.

21. Murphy PB, Rehal S, Arbane G, Bourke S, Calverley PM, Crook $\mathrm{AM}$, et al. Effect of home noninvasive ventilation with oxygen therapy vs oxygen therapy alone on hospital readmission or death after an acute COPD exacerbation: a randomized clinical trial. JAMA 2017;317:2177-86.

22. Murphy PB, Suh ES, Hart N. Non-invasive ventilation for obese patients with chronic respiratory failure: are two pressures always better than one? Respirology 2019;24:952-61.

23. Hess DR. Respiratory care: principles and practice. 2nd ed. Sudbury: Jones \& Bartlett Learning; 2012.

24. Gramlich T. Basic concepts of noninvasive positive pressure ventilation. In: Pilbeam SP, Cairo JM, editors. Mechanical ventilation: physiological and clinical applications. 4th ed. Philadelphia: Mosby Elsevier; 2006. p. 417-40.

25. Ellis ER, Bye PT, Bruderer JW, Sullivan CE. Treatment of respiratory failure during sleep in patients with neuromuscular disease: positive-pressure ventilation through a nose mask. Am Rev Respir Dis 1987;135:148-52.

26. Ellis ER, McCauley VB, Mellis C, Sullivan CE. Treatment of alveolar hypoventilation in a six-year-old girl with intermittent positive pressure ventilation through a nose mask. Am Rev Respir Dis 1987;136:188-91.

27. McEvoy RD, Thornton AT. Treatment of obstructive sleep apnea syndrome with nasal continuous positive airway pressure. Sleep 1984;7:313-25.

28. Sullivan CE, Berthon-Jones M, Issa FG. Remission of severe obesity-hypoventilation syndrome after short-term treatment during sleep with nasal continuous positive airway pressure. Am Rev Respir Dis 1983;128:177-81.

29. Sullivan CE, Issa FG, Berthon-Jones M, Eves L. Reversal of obstructive sleep apnoea by continuous positive airway pressure applied through the nares. Lancet 1981;1:862-5.

30. Sanborn WG. Microprocessor-based mechanical ventilation. Respir Care 1993;38:72-109.

31. Richard JC, Carlucci A, Breton L, Langlais N, Jaber S, Maggiore $S$, et al. Bench testing of pressure support ventilation with three different generations of ventilators. Intensive Care Med 2002;28:1049-57.

32. Criner GJ, Brennan K, Travaline JM, Kreimer D. Efficacy and compliance with noninvasive positive pressure ventilation in patients with chronic respiratory failure. Chest 1999;116:66775.

33. Rabec C, Rodenstein D, Leger P, Rouault S, Perrin C, Gonzalez-Bermejo J, et al. Ventilator modes and settings during noninvasive ventilation: effects on respiratory events and impli- 
cations for their identification. Thorax 2011;66:170-8.

34. Storre JH, Huttmann SE, Ekkernkamp E, Walterspacher S, Schmoor C, Dreher M, et al. Oxygen supplementation in noninvasive home mechanical ventilation: the crucial roles of CO2 exhalation systems and leakages. Respir Care 2014;59: 113-20.

35. Murate T, Mizoguchi K, Amano H, Shimokata K, Matsuda T. Antipurified-protein-derivative antibody in tuberculous pleural effusions. Chest 1990;97:670-3.

36. Carlucci A, Schreiber A, Mattei A, Malovini A, Bellinati J, Ceriana $\mathrm{P}$, et al. The configuration of bi-level ventilator circuits may affect compensation for non-intentional leaks during volume-targeted ventilation. Intensive Care Med 2013;39:5965.

37. Khirani S, Louis B, Leroux K, Delord V, Fauroux B, Lofaso F. Harms of unintentional leaks during volume targeted pressure support ventilation. Respir Med 2013;107:1021-9.

38. Borel JC, Sabil A, Janssens JP, Couteau M, Boulon L, Lévy P, et al. Intentional leaks in industrial masks have a significant impact on efficacy of bilevel noninvasive ventilation: a bench test study. Chest 2009;135:669-77.

39. Fernandez Alvarez R, Rubinos Cuadrado G, Rodriguez Jerez F, Garcia Garcia A, Rodriguez Menendez P, Casan Clara P. Home mechanical ventilation through mask: monitoring leakage and nocturnal oxygenation at home. Respiration 2013;85:132136.

40. Miyoshi E, Fujino Y, Uchiyama A, Mashimo T, Nishimura M. Effects of gas leak on triggering function, humidification, and inspiratory oxygen fraction during noninvasive positive airway pressure ventilation. Chest 2005;128:3691-8.

41. Contal O, Vignaux L, Combescure C, Pepin JL, Jolliet P, Janssens JP. Monitoring of noninvasive ventilation by built-in software of home bilevel ventilators: a bench study. Chest 2012; 141:469-76.

42. Luján M, Lalmolda C, Ergan B. Basic concepts for tidal volume and leakage estimation in non-invasive ventilation. Turk Thorac J 2019;20:140-6.

43. Luján M, Sogo A, Pomares X, Monsó E, Sales B, Blanch L. Effect of leak and breathing pattern on the accuracy of tidal volume estimation by commercial home ventilators: a bench study. Respir Care 2013;58:770-7.

44. Chatburn RL. Classification of mechanical ventilators. In: Tobin MJ, editor. Principles and practice of mechanical ventilation. 2nd ed. New York: McGraw Hill; 2006. p. 37-52.

45. Hess DR. Ventilator waveforms and the physiology of pressure support ventilation. Respir Care 2005;50:166-86.

46. Calderini E, Confalonieri M, Puccio PG, Francavilla N, Stella L, Gregoretti C. Patient-ventilator asynchrony during noninvasive ventilation: the role of expiratory trigger. Intensive Care Med 1999;25:662-7.

47. Johnson KG, Johnson DC. Treatment of sleep-disordered breathing with positive airway pressure devices: technology update. Med Devices (Auckl) 2015;8:425-37.

48. Ferguson GT, Gilmartin M. CO2 rebreathing during BiPAP ventilatory assistance. Am J Respir Crit Care Med 1995;151: 1126-35.

49. Lofaso F, Brochard L, Touchard D, Hang T, Harf A, Isabey D. Evaluation of carbon dioxide rebreathing during pressure support ventilation with airway management system (BiPAP) devices. Chest 1995;108:772-8.

50. Blakeman TC, Branson RD. Evaluation of 4 new generation portable ventilators. Respir Care 2013;58:264-72.

51. Mandal S, Ramsay M, Suh ES, Harding R, Thompson A, Douiri A, et al. External heated humidification during non-invasive ventilation set up: results from a pilot cross-over clinical trial. Eur Respir J 2020;55:1901126.

52. Blakeman TC, Rodriquez D Jr, Hanseman D, Branson RD. Bench evaluation of 7 home-care ventilators. Respir Care 2011; 56:1791-8

53. Make BJ, Hill NS, Goldberg AI, Bach JR, Criner GJ, Dunne PE, et al. Mechanical ventilation beyond the intensive care unit. Report of a consensus conference of the American College of Chest Physicians. Chest 1998;113:289S-344S.

54. Senent C, Lepaul-Ercole R, Chiner E, Lamouroux C, Similowski T, Gonzalez-Bermejo J. Home mechanical ventilators: the point of view of the patients. J Eval Clin Pract 2010;16:832-4.

55. Muñoz-Bonet JI, López-Prats JL, Flor-Macián EM, Cantavella T, Bonet L, Domínguez A, et al. Usefulness of telemedicine for home ventilator-dependent children. J Telemed Telecare 2020; 26:207-15. 